\title{
DISCUSSION (Hill and Adelman)
}

WEHLAU: Have you made any studies of systematic photographic errors which might persist from plate to plate, such as at the edges of sharp features?

ADEIMAN: I have intercompared very limited regions of the spectra which I have coadded, to look for obvious problems. I intend to make additional checks for photographic problems which might lead to systematic errors. In particular, I plan to obtain parts of these spectra at the 1.2-m telescope at DAO with their Reticon to check the coaddition process. So far, I have not found any problems.

MEGESSIER: I have a technical question concerning the PDS microdensitometer work. According to my experience, the most timeconsuming problem is the focusing of the plate. I can not adjust and trace eight plates in one hour!

ADEIMAN: The PDS microdensitometer at DAO has lenses with a relatively large depth of field. This, plus some tape strategically placed around the edges of the plate, usually allows one to obtain good focus over the entire plate. I have had problems similar to yours at Kitt Peak, and I was able to get good focus over only 4 inches $[10 \mathrm{~cm}]$ of spectrogram. DWORETSKY: I had the same problem (out-of-focus plates) when I used the PDS at the Royal Greenwich Observatory some years ago. The designers have not allowed for the fact that the photographic emulsion on a developed plate shrinks a bit, so that the plate is slightly curved. The PDS machine has no stage clips for holding the plate down. Our solution was to construct a weighted ring with clips (cut from a broken clock's main spring) to hold the plate down. This was an inexpensive way of solving the problem.

ADELMAN: It is true that plates do curl, and we even had a few plates where for some reason the emulsion shrinkage produced a twist, which made life very difficult.

C. R. Cowley et al (eds.), Upper Main Sequence Stars with Anomalous Abundances, 217.

(C) 1986 by D. Reidel Publishing Company. 